Results 402 infants died during the period 1/1998-12/2012 and 239 had an autopsy (59.4\%). The mean value of days-of age-atdeath in infants with autopsies was $9.8 \pm 23$ days, CI $95 \%$ (6.8-12.9) vs. $18.3 \pm 28$ days CI 95\% (13.9-22.6) for cases without autopsy, $\mathrm{p}<0.01$. Group A had a high percentage of cases with autopsy: 115/ 171 (67\%) In group D a low percentage of cases had an autopsy: 13/46 (28\%). Using Kruskal Wallis rank test differences between Group A and group D were significant $(\mathrm{p}<0.001)$.

Conclusions Autopsy rates in infants dying during the first 2 days of life were significantly higher than rates after 28 days of life. Reasons for these differences need to be evaluated in a prospective manner that should include social, educational, religious and behavioural aspects of parents and caregivers.

\section{PO-0652 NEW NEONATAL RESUSCITATOR GIVES MORE LUNG VOLUME ON A MANNEQUIN MODEL}

${ }^{1} \mathrm{M}$ Thallinger, ${ }^{2} \mathrm{H}$ Ersdal, ${ }^{3} \mathrm{~K}$ Stordal. ${ }^{1}$ Institute for Experimental Medical Research, University of Oslo, Oslo, Norway; ${ }^{2}$ Department of Anaesthesiology and Intensive Care, Stavanger University Hospital and SAFER, Stavanger, Norway; ${ }^{3}$ Department of Genes and Environment, Norwegian Institute of Public Health, Oslo, Norway

\subsection{6/archdischild-2014-307384.1293}

Background Bag mask ventilation of the newborn is the most difficult part of neonatal resuscitation, as experienced in the Helping Babies Breathe program. Methods to facilitate improved bag mask ventilation and aid training are therefore needed.

Methods 41 nursing and medical students without any knowledge of newborn resuscitation were trained in basic bag mask ventilation and ventilated with the two devices; a new Upright resuscitator (Laerdal Global Health, Stavanger) and a standard newborn resuscitator (Laerdal Medical, Stavanger) on a manikin in random order. Ventilation data was collected with the Newborn Resuscitation Monitor (Laerdal Global Health) and analysed for 40 students. One was omitted due to inaccurate data signal reading. The students answered questions grading mask seal (1) and ease of air entry (2) from 1 (difficult) to 4 (easy) and finally which device they preferred.

Results 31 of $41(76 \%)$ students preferred the Upright resuscitator. For "mask seal" mean score was 3 for Upright and 2.5 for standard (one sample binomial test $p=0.03$ ), and for "ease of air entry" 3.5 for Upright and 3.2 for standard $(p=0.05)$. Mean expired lung volume was $15.5 \mathrm{ml}$ for Upright and 13.8 for standard resuscitator with mean difference $1.7 \mathrm{ml}$ (95\% confidence interval 3.2-0.2, one sample t-test for paired observations $\mathrm{p}=0.03)$. Mean mask leakage for Upright was $46 \%$ and standard 60\% (paired sample test $\mathrm{p}<0,001$ ).

Conclusion The students showed a preference towards the Upright resuscitator, which also provided a slightly higher expiratory volume and significantly reduced mask leakage compared to the standard resuscitator.

\section{PO-0653 THE PERIODONTAL PATHOGENS IN THE SALIVA OF ONE-YEAR-OLD INFANTS DELIVERED WITH VERY LOW BIRTH WEIGHT}

${ }^{1} \mathrm{H}$ Tobrmanová, ${ }^{2} \mathrm{~V}$ Merglova, ${ }^{1} \mathrm{~J}$ Dort. 'Department of Neonatology, University Hospital, Pilsen, Czech Republic; ${ }^{2}$ Department of Dentistry, Faculty of Medicine, Pilsen, Czech Republic

10.1136/archdischild-2014-307384.1294
Aim The aim of this study is to identify the presence of main periodontal pathogens in the oral cavity of 12-month-old infants and compared the occurrence of these microbes between a cohort of very low birth weight infants and a control cohort.

Methods The research cohort was composed of 69 one-year-old infants, 24 of whom were born prematurely with very low birth weight and 45 of whom were born at term. At 12 months of age, both groups of infants were examined, and unstimulated saliva samples from the dorsum of the tongue and dental plaque samples were collected. The periodontal pathogens Aggregatibacter actinomycetemcomitans, Porphyromonas gingivalis, Tannerella Forsythensis, Treponema denticola, Peptostreptococcus micros, Prevotella intermedia and Fusobacterium nucleatum were identified using a PCR-based method. Chi-square and Fisher's factorial tests were used for the statistical evaluation.

Results Periodontal pathogens were present in $83 \%$ of the preterm infants and $96 \%$ of full-term infants. Aggregatibacter actinomycetemcomitans was the most common periodontal pathogen found in the oral cavities of the infants enrolled in our study. No statistically significant differences between the preterm infants and the full-term infants were found regarding the presence of periodontal pathogens.

Conclusions The study confirmed the early transmission of periodontal pathogens to the oral cavity of one-year-old infants. Future research should focus on establishing the clinical importance of periodontal pathogens in the saliva of infants and their role in the aetiology of early onset periodontal disease.

The study was supported by grant IGA of Ministry of Health Czech Republic, NT 14336-3.

\section{P0-0654 DELAYED BIRTH OF NEXT SIBLING IN FAMILIES WITH A PRETERM CHILD: ROLE OF OBSTETRIC HISTORY}

${ }^{1} \underline{S}$ Turkka, ${ }^{1} \mathrm{P}$ Näsänen-Gilmore, ${ }^{2} \mathrm{M}$ Vääräsmäki, ${ }^{3} \mathrm{M}$ Gissler, ${ }^{2} \mathrm{~A}$ Pouta, ${ }^{1} \mathrm{E}$ Kajantie, ${ }^{1} \mathrm{P}$ Hovi. ${ }^{1}$ Department of Chronic Disease Prevention, National Institute for Health and Welfare (THL), Helsinki, Finland; ' 2 Department of Obstetrics and Gynecology, National Institute for Health and Welfare (THL), Oulu, Finland; ${ }^{3}$ Department of Support Services, National Institute for Health and Welfare (THL), Helsinki, Finland

\subsection{6/archdischild-2014-307384.1295}

Background Prematurity postpones the birth of a subsequent sibling. This phenomenon is strongest in mothers with long prior interbirth interval, a proxy of fertility problems.

Aim We assessed whether a history of miscarriages explains the postponed birth of next sibling after preterm birth.

Methods We obtained pregnancy and newborn data from Finnish Medical Birth Register (Jan 1, 1987 - Sep 30, 1990). Sibling data came from the National Population Register Centre.

Of the total of 230378 singleton births we excluded 1242 $(0.5 \%)$ due to death before 1 yrs. GA was missing for 2922

\begin{tabular}{llll}
\multicolumn{4}{l}{ Abstract PO-0654 Table 1} \\
Miscarriages \\
GA & $\mathbf{n}$ (subjects) & $\mathbf{n}$ (misc.) & $\%$ within GA group \\
$<28$ & 235 & 76 & 32,3 \\
$28-31$ & 793 & 186 & 23,5 \\
$32-37$ & 8360 & 1638 & 19,6 \\
$38-42$ & 206640 & 35237 & 17,1 \\
$>42$ & 9622 & 1467 & 15,2 \\
& & & \\
total & 225650 & 38604 & 17,1 \\
\hline
\end{tabular}




\begin{tabular}{llll}
$\begin{array}{l}\text { Abstract PO-0654 Table 2 Adjusted } \\
\text { sibling birth }\end{array}$ & model estimating next \\
\hline Variable* & HR & $\begin{array}{l}95 \% \text { CI for Exp (B) } \\
\text { Lower }\end{array}$ & Upper \\
& & 0.97 & 1.00 \\
Male & 0.99 & 0.54 & 0.81 \\
$<28$ & 0.66 & 0.66 & 0.82 \\
$28-31$ & 0.74 & 0.90 & 0.95 \\
$32-37$ & 0.93 & 1.17 & 1.23 \\
$>42$ & 1.20 & 0.76 & 0.79 \\
\hline Miscarriages & 0.77 & &
\end{tabular}

(1.3\%) and miscarriage data for 2964 (1.3\%); 225650 children remained in analyses.

We utilised Cox regression for proportional hazards to analyse the effect of GA and history of miscarriages on sibling birth. Results A low GA at birth delayed subsequent sibling birth. The effect remained unchanged after introducing miscarriages in the model.

*Numbers indicate completed gestational weeks. HR, Hazard Ratio (term group, females and no miscarriages as a referent). Conclusions Prematurity postponed subsequent sibling birth. Accounting for obstetric history left this effect unchanged.

\section{PO-0655 THE EFFICACY OF SNAPPE-II IN PREDICTING MORBIDITY AND MORTALITY IN EXTREMELY LOW BIRTH WEIGHT INFANTS}

S Ucar, M Varma, MI Ethemoglu, NK Acar. Department of Pediatrics, OSM Middle East Hospital, Sanliurfa, Turkey

\subsection{6/archdischild-2014-307384.1296}

Background and aims Various scoring system are used to predict morbidity and mortality. Among these the "Score for Neonatal Acute Physiology-Perinatal Extension-II" (SNAPPE-II) predicts the risk of mortality based on data collected within the first day of the newborn. We aimed to determine the efficacy of SNAPPE-II in predicting mortality in extremely low birth weight infants (ELBW). We also assessed its efficacy in predicting the potential causes of neonatal morbidity.

Methods Data from infants admitted between June 2012 and June 2013 to the neonatal intensive care unit with a birth weight less than $1500 \mathrm{gr}$ were collected in a retrospective manner. SNAPPE-II score was calculated for the first $24 \mathrm{~h}$ of each infant. The efficacy of SNAPPE-II score in predicting intra ventricular haemorrhage (IVH), necrotizing enterocolitis (NEC) and bronchopulmonary dysplasia (BPD) as well as mortality was evaluated.

Results A total of 182 infants (98 males and 84 females) were enrolled in the study. Mean birth weight was 1,134 $\pm 264 \mathrm{~g}$. The most notable scores documented for SNAPPE-II were 33 for mortality (sensitivity $86.6 \%$, specificity 76,4\%), 23 for IVH (sensitivity $88.2 \%$, specificity 64.6\%), 39 for NEC (sensitivity $78.7 \%$,specificity $72.6 \%$ ) and 36 for BPD (sensitivity $87,8 \%$, specificity $69,4 \%)$. Infants with a high SNAPPE-II score had significantly higher rates of IVH $(p<0,001)$, NEC $(p=0,014)$ and BPD ( $\mathrm{p}=0,003)$.

Conclusions We found that a high score of SNAPPE-II in premature infants was independently associated with neonatal mortality as well as with factors know to be associated with neonatal morbidity, such as IVH, NEC and BPD.

\section{P0-0656 THE EVALUATION OF 263 NEWBORNS WITH MENINGOMYELOCELE: FIVE YEARS OF EXPERIENCE}

'S Ucar, ${ }^{1} \mathrm{M}$ Varma, ${ }^{2} \mathrm{M}$ Gok, ${ }^{2} \mathrm{~B}$ Celik, ${ }^{3} \mathrm{~A}$ Yesilay. ${ }^{1}$ Department of Pediatrics, OSM Middle East Hospital, Sanlurfa, Turkey; ${ }^{2}$ Department of Neurosurgery, OSM Middle East Hospital, Sanlurfa, Turkey; ${ }^{3}$ Department of Anesthesiology, OSM Middle East Hospital, Sanlurfa, Turkey

\subsection{6/archdischild-2014-307384.1297}

Background and objectives Meningomyelocele (MMC) is a congenital malformation characterised by the herniation of a part of the spinal cord with surrounding meningeal structures as a sac through an open spinal canal. In this study we aimed to evaluate the demographic and clinical features of MMC cases followed in our neonatal intensive care unit, to investigate the accompanying congenital malformations and the effects of operation timing on mortality and morbidity.

Methods Patients between January 2009 and January 2014 were evaluated retrospectively. The patients were analysed according demographic features, additional malformations, operation timing and the ratio of an additionally ventriculoperitoneal shunt placement because of concomitant hydrocephaly. The effects of operation timing on mortality, complications and the lenght of hospital stay were investigated.

Results 263 patients were included in this study 152 male (57.8\%), 111 female (42.2\%). The ratio of prenatal diagnosis was $77.2 \%$ and the paternal consanguinity ratio was $51.3 \%$. Ventriculoperitoneal shunting was performed to $72.6 \%$ of the patients after the MMC surgery. The lenght of hospital stay, total period of antibiotic use and the mortality ratio were significantly lower in the cases among whom the operation time was less than three days ( $\mathrm{p}$ values are $0.006,0.014,0.004$ respectively).

Conclusions The ratio of births with MMC is higher in our city when compared with another countries and the high ratio of paternal consanguinity imight be responsible for this difference and. The mortality and rate of complications can be decreased by early performing of MMC surgery.

\section{PO-0657 ASSESSMENT OF EXTREMELY LOW BIRTH WEIGHT INFANTS IN A NEONATAL INTENSIVE CARE UNIT OF A TERTIARY REFERRAL HOSPITAL}

S Ucar, IH Baysal, M Varma, S Gunes. Department of Pediatrics, OSM Middle East Hospital, Sanliurfa, Turkey

\subsection{6/archdischild-2014-307384.1298}

Background and aims Due to severe postnatal complications, the morbidity and mortality rate of extremely low birth weight (ELBW) premature infants remains significantly high. We aimed to assess the morbidity and mortality rates as well as the demographic characteristics of ELBW infants admitted to a neonatal intensive care unit (NICU).

Methods ELBW infants admitted to the NICU between March 2010 and 2013 were included in the current study. Demographic characteristics, the type of surfactant and the need for a repeat dose, the need for mechanical ventilation and etiologic factors associated with morbidity and mortality were retrospectively assessed.

Results A total of 134 infants were enrolled in the study. Mean birth weight was $836 \pm 155 \mathrm{~g}$ and mean gestational week was $26.4 \pm 1.7$ weeks. While all the infants received surfactants, $41.8 \%$ were treated with beractant, and $58.2 \%$ with proctant alfa. Overall mortality rate was $59.7 \%$. The need for repeated 